\title{
Meningococcal salpingitis
}

\author{
F. E. WILLMOTT \\ Leicester Royal Infirmary
}

\section{Summary}

In a case of acute salpingitis a cervical smear showed Gram-negative diplococci but culture showed Neisseria meningitidis, which was also cultured from the throat swab. It is suggested that $N$. meningitidis was the cause of the salpingitis in this case.

\section{Introduction}

The different species of Neisseria are known to show a predilection for various sites in the body. However, isolation of Neisseria gonorrhoea from the throat and Neisseria meningitidis from the genital tract is being reported with increasing frequency. These reports show the importance of identifying the species of Neisseria involved.

\section{Case report}

A Caucasian woman aged 19 years attended this Clinic in March, 1975, as a contact of a male patient (75/733) who had presumptive gonococcal urethritis. She complained of lower abdominal pain for 1 week and vaginal discharge. There was a history of receiving ampicillin 3 months previously for an episode of urinary symptoms diagnosed as cystitis.

Examination There was cervicitis with a purulent vaginal discharge. Vaginal examination revealed a tender swelling in the left fornix. The temperature was $37 \cdot 6^{\circ} \mathrm{C}$. and the pulse rate $100 / \mathrm{min}$. There was tenderness in the left iliac fossa but no guarding or rebound tenderness.

Diagnosis Cervical smear showed extracellular Gramnegative diplococci. A presumptive diagnosis of gonococcal salpingitis was made.

Treatment She was given ampicillin $2 \mathrm{~g}$. and Probenecid $1 \mathrm{~g}$. initially followed by ampicillin $0.5 \mathrm{~g}$. four times a day for 5 days.

Laboratory investigations $\mathrm{Hb} 12.5 \mathrm{~g}$. per cent. White cell count 9,000 . Erythrocyte sedimentation rate $60 \mathrm{~mm} . / 1 \mathrm{st}$

hr. Gonococcal complement-fixation test negative. Cervical culture showed $N$. meningitidis. Throat swab taken at the initial attendance also showed $N$. meningitidis. Both had the same sensitivity, showing resistance to sulphafurazole, Neomycin, Polymixin, and Cotrimoxazole.

(Viral culture from the cervix grew cytomegalovirus and the cytomegalovirus complement-fixation test was positive $1: 256$. There was a history of 'glandular fever' diagnosed by her general practitioner 1 year previously.)

Result Repeat smears and cultures were negative for Neisseria 1 week, 3 weeks, and 2 months after treatment.

\section{Sexual partners}

Two male consorts were seen but both unfortunately before the female patient. She had originally been named 2 months before her attendance by a male patient $(75 / 728)$ who was diagnosed as having gonococcal urethritis, the diagnosis having been made by Gram-stained smear only. The other consort (75/733), who was seen 2 days before she attended had a purulent urethral discharge. Urethral smear showed intracellular and extracellular Gramnegative diplococci. The discharge was cultured and Neisseria were grown, but as the man was single, there were no medicolegal sanctions, so that sugar fermentation reactions were not performed and the culture was discarded. Throat swabs were not taken from either consort.

\section{Gonococcal culture methods}

Swabs from the urethra, cervix, and throat were inoculated on to Oxoid G. C. selective media and incubated in candle-extinction jars at $37^{\circ} \mathrm{C}$ for $48 \mathrm{hrs}$. Oxidase-positive colonies were Gram-stained and sent for identification. Sugar fermentation reactions were performed using sugars in seum-free medium (Flynn and Waitkins, 1972) in $3 \mathrm{ml}$. amounts in bijou bottles. The sugars glucose, maltose, sucrose, lactose, and salicin were incubated and examined at 24 and 48 hrs. Control tests, identical except for the omission of sugars from the media, were performed at the same time.

\section{Discussion}

The initial clinical findings were indications of salpingitis. The presence of $N$. meningitidis suggested that this organism was the cause and the rapid 
response to ampicillin supported this diagnosis. The isolation of $N$. meningitidis from the cervix is well documented both in an asymptomatic state (Lewis and Alexander, 1974) and as a cause of disease (Carpenter and Charles, 1942; Keys, Hecht, and Chow, 1971; Givan and Keyl, 1974; Beck, Fluker, and Platt, 1974). There are no reports of its association with salpingitis. It would seem likely than an organism responsible for urethritis in a man would also be responsible for cervicitis in his regular female consort and vice versa. Had $N$. meningitidis been identified in the male cases of urethritis this would have provided added support.

I am indebted to Dr. E. M. Stirk and the staff of the Microbiology Department of the Leicester Royal Infirmary for the identification of the organisms, and to Dr. Helen J. Mair for the virological investigations.

\section{References}

Beck, A., Fluker, J. L., and Platt, D. J. (1974) Brit. F. vener. Dis., 50, 367

Carpenter, C. M., and Charles, R. (1942) Amer. $\mathcal{F}$. publ. Hlth, 32, 640

FlynN, J., and Waitkins, S. A. (1972) f. clin. Path., 25, 525

Givan, K. F., and KeYL, A. (1974) Canad. med. Ass. F., 111, 1077

KeYs, T. F., HeCht, R. H., and Chow, A. W. (1971) New Engl. F. Med., 285, 505

Lewis, J. F., and AleXander, J. J. (1974) Amer. f. clin. Path., 61, 216 